\title{
Vakıf ve Sanat Paneli
}

Ahmet Kılıç*

Vakıflar Genel Müdürlüğü, her yıl bir tema çerçevesinde düzenlediği etkinliklerle Vakıf Medeniyetini topluma anlatma çalışmalarını bu yıl da "Vakıf ve Sanat" teması ile gerçekleştirmiştir. Bu etkinlikler kapsamında 12 Mayıs 2015 tarihinde Vakıflar Genel Müdürlüğü Konferans Salonunda "Vakıf ve Sanat" konulu panel düzenlenmiş ve konularının uzmanı hocalarımız tebliğlerini sunmuştur.

Panelin oturum başkanı, Fatih Sultan Mehmet Vakıf Üniversitesi Güzel Sanatlar Fakültesi Dekanı Prof. Dr. Hüsrev SUBAŞI, Vakıf ve Sanat terimlerini esas alarak yaptığı açılış konuşmasında Vakfi; "hayat kolaylaştırarak Allah'ın rızasına ulaşma arzusu" sanat ise; "hayat güzelleştirme çalışması" olarak tanımlamış ve konuşmasında özetle şu konulara değinmiştir;

"Vakıf, insanın bedensel, sanat ise ruhsal hayatını inşa etme faaliyetlerini sürdürmekte, nihai olarak vakfin ve sanatin varmak istediği hedef ilahi bir noktada birleşmektedir.

Vâkıflar eserlerin yalnızca fonksiyonelliğinin yerine getirilmesi kolaycılığına gitmeyerek eserdeki her bir unsura sanatla ruh verdiğinden sanat, vakıf eserlerinde can bulmuştur.
Sanat pahalı bir alan olduğundan, hayatında sanata yer vermek isteyenlerin kesesinin ağzını açması ve kaliteli kişilerle çalışması bir zorunluluktur. Ortaya çıkan vakıf eserlerin, hat, tezyin ve işçilik detaylarına bakarak vakıf kültürünün sanatçıyı ve dolayısıyla sanatı finanse ettiğinin görüldüğünü" ifade etmiştir.

Panelistlerden ilk tebliği, Yıldırım Beyazıt Üniversitesi İslami Illimler Fakültesi Dekanı Prof. Dr. Mehmet AKKUŞ “Vakfiyelerde Söz Sanat" başlığı ile sunmuştur.

Akkuş, vakfiyelerde geçen; "Bizim yaptı̆̆ımız bu eserler bizi tanıtmaktadır, eğer bizi tanımak istiyorsanız o halde siz de bu eserlere bakarak bizleri tanıyın" ifadesi ile başladığı sözlerini, özetle, şu konulara değinerek sürdürmüştür;

"Bu vakfiyelerde bir sanat yok, birçok sanatın bir arada toplandığı yer olarak kabul etmek gerekir. Vakfiyelere dıştan içe doğru bakacak olursak dış kapak, tezhib, serlevha ve hatları başlı başına birer sanat eseri olan bu unsurları bir tarafa koyarak sadece söz sanatından bahsetmek hiç uygun düşmez.

Vakfiye metinlerinde birkaç bölüm vardır; birinci olarak hamd ve sena kısmı var. Cenab-ı Hakk'a

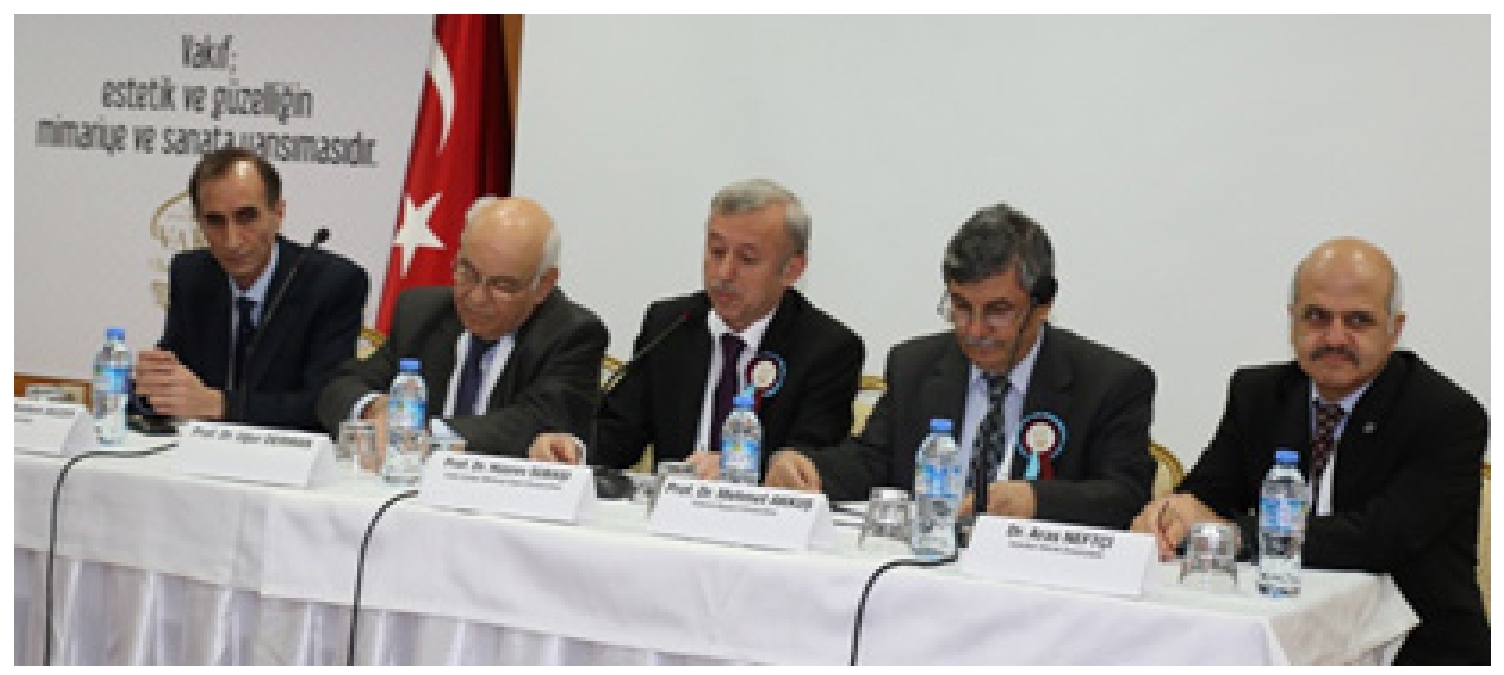

* Kütüphaneci, Vakıflar Genel Müdürlüğü, a.kilic@vgm.gov.tr 
hamd ve senayı işlerken o kadar güzel hamd ve senayı işlemişler ki zaten birazdan sözü onlara bı-

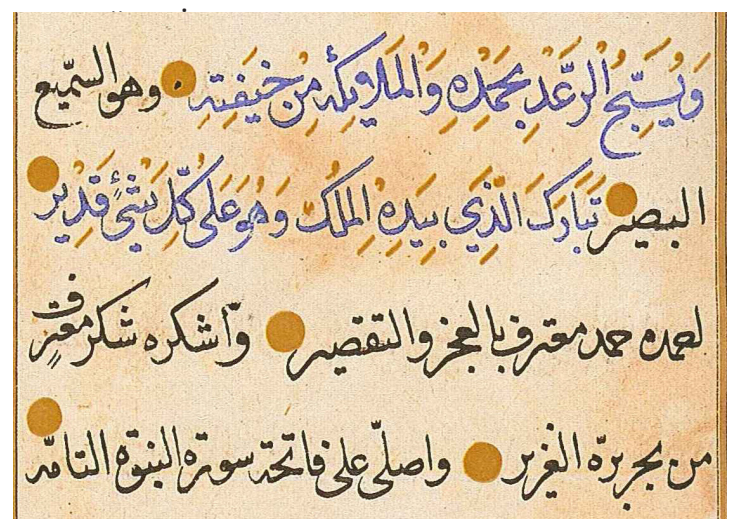

Resim 1. Fatih Sultan Mehmet Han'ın Eyüp Vakfiyesi'nden bir bölüm.

Son derece edibane yazılmış kısımlar var bunlara bir kaç örnek verecek olursak:

"Nesim-i anber şerîni hamd-i sipâs, Ve güldeste-i mürişdîni sena-ı şükr-i bî-kıyâs, Ol mâlikü'l-mülkü zü'l-celâli ve celîlü'l-celâl vâcibü'l-iclâl, Pâdişâh-ı bî-zevâl amîmü'n-nevâl, Tenezzeheb zâtthû ani'ş-şebîhi ve'l-misâl hazretlerine lâyık ve seza ve şâyeste-i revadır ki; Nüsha-i insanı eblağ-ı üslubda ve ahsen-i takvimde inşa '..."
Bunların kelime kelime anlatılması çok vakit alacağından diğer kısımlardan örnek vermeye devam edelim;

"Vâkıf-ı esrâr-ı ins-ü cân hazretlerine lâyık ve sezâ ve elyab ve ahrâdır ki; Nüsha-i insanı eblağ-ı üslubda imlâ ve ahsen-i takvimde inşa ...."

Düzyazı içerisindeki şiirsel söyleyişe en güzel örneklerden, Kanuni Vakfiyesinden de bir parçaya bakacak olursak;

"Dünya dâr-ı devâru medâr-ı imâr, Mahall-i tebâru karatu'l-aktârdır. Fezâsı kaza ile meşhur, Sefası ise cefa ile makrûr. Finâsı fenaya karîm, Ğınası anâya rehîn. Nimeti nikmete, minhati mihnetine muhavvel. Sihhati sahame, felahı feraha. Desen-i sem, ni'amı gam. Şarâbı serâb, Âmiri harâb. Meta-ı gurur, sürûr-u gurur..."

Buna benzer ifadeler ile dünyanın geçiciliği örneklendirildikten sonra en sonunda diyor ki;

"... ve ma'azâlik haber-i sıdk-ı eserî, ed-dünyâ mezraat'l-ahire mistâkınca, mahalli ittihal zahire-i uhrâ, mezraa-ı ahiret ve meccele-i uhrâdır..."

Dedikten sonra malını neden vakfettiğini yine şiirsel bir ifadeyle anlatmaktadır.

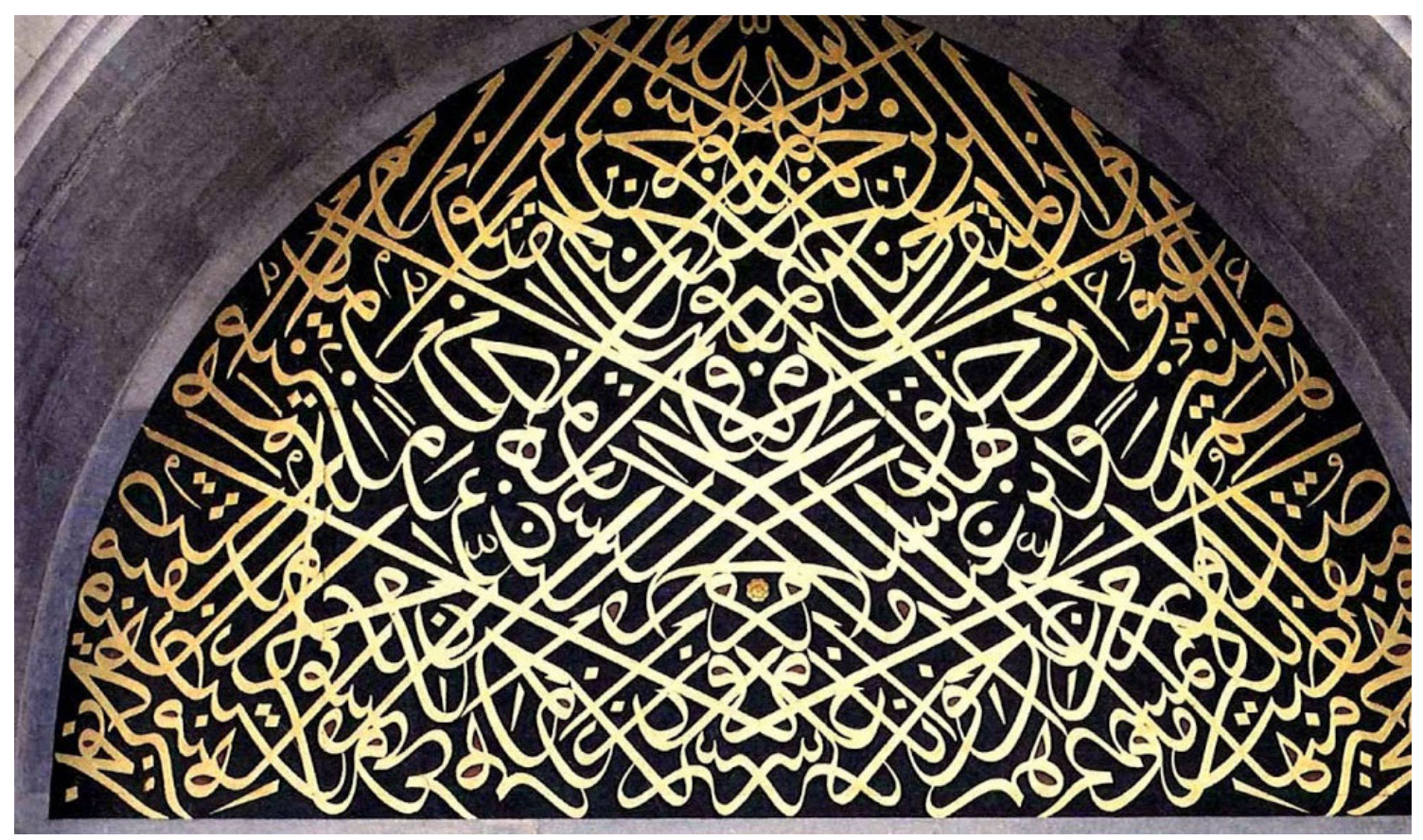

Resim 2. Topkapı Sarayı giriş kapısı üzerindeki müsenna celi sülüs yazı. 
Vâkıf malını niçin vakfettiğini ayet ve hadislerden alıntılarla, şiirsel bir tarzla ifade etmektedir." diyerek teşekkür eden Akkuş sözü panel başkanına bırakmıştr.

İkinci olarak Prof. Dr. Uğur DERMAN “Medresetül Hattatinin Yüzüncü Yılı ve Vakıf Eserlerde Hat Sanat" başlıklı tebliğini sunmuştur.

"Osmanlı bir vakıf medeniyetidir ve hüsnü hatta onun anahtarıdır" diyen Derman, tebliğinin hülasasının bu cümle içerisinde bulunduğunu belirterek konuşmasına, özetle, şöyle devam etmiştir;

"Osmanlı medeniyetinde hattı şöyle bir rolü vardır; hat, okuma yazma vesilesidir. Osmanlı'da okuma yazma bilen sayısı azdır ama bilen de tüm özellikleriyle bilirdi. Hat sanatına meyleden bir genç üstadın yanına giderek öğrenme isteğini bildirir, hoca da bedelsiz olarak onu meşk etmeye çağırarak öğrencisini yetiştirirdi.

Sözü fazla uzatmadan size, seçtiğim hat eserlerini anlatmaya çalışacağım.

İlk olarak, Topkapı Sarayı giriş kapısı üzerindeki Fatih devrinden kalma müsenna celi sülüs yazıyı göstermek isterim bu yazı, grafik örülüş itibariyle hala geçilememiştir, Fatih devri hattatı Ali Sofi'ye aittir.

Nesih hatt diğer hat sanatları gibi Abbasilerden itibaren, zaman içinde oluşmuş, İstanbul'un fethinden sonra Şeyh Hamdullah ile kemâl bulmuştur.

Sultanahmet Camii'nin kitabesi, celi hatla yazımıştır. Cami ve bina kitabeleri celi hatla yazılır ve son mısraına tarih düşülürdü. 1927'de Meclis'ten çıkan bir kanunla bu kitabeler kazınarak yok edilmiştir. Hüsn-ü hattı Şeyh Hamdullah'tan sonra gelen deha derecesindeki üstatlarından bir tanesi de Hafiz Osman'dır. Kendisi de bir hattat olan Sultan III. Ahmet'in Topkapı Sarayı girişi önündeki çeşme için yazdığı celi sülüs yazı da kıymetini muhafaza etmektedir.

18. asrın ikinci yarısı, on dokuzuncu asrın başlarında hakikaten bir deha olan Hattat Rakımdır ki; ben hat sanatını Rakım'dan önce ve Rakım'dan sonra diye tasnif etmeyi doğru buluyorum. Rakım'dan sonra celi yazılar tekâmül ettiği zaman
Kazasker Mustafa İzzet Efendi'nin yazmış olduğu bu cami yazıları daha da revaç bulmuş ve daha da güzel yazılmaya başlanmıştır. Ayasofya'da bulunan bu büyük yazılar 1944 yılında müze iken ziyarete gittiğimizde yerlerinden indirilmiş ve duvarlara yaslı olarak durmaktaydı, babam "bunlar nede yerde" diye sorduğunda bir görevli "bunlar dışarı çıkarılacaktı ancak içerde çatıldığından kapıdan sığmadığı için çıkarılamadı bu nedenle yerde duruyor" demişti, 1952 yılında ise tekrar yerlerine çıkarılmıştır.

20. asrın en büyük ismi diyebileceğimiz Halil Özyazıcı'nın Yavuz Selim Camii'ne yazığı kubbe yazısı da Rakım sonrası devrin güzel örneklerindendir. Bu dönemde yazı zeminlerinde çoğunlukla ördekbaşı yeşili olmakla fes rengi, gülkurusu ve az da olsa mavi renk kullanılmıştir ve bu sayede altın varakla yazılan yazı zemin içerisinde patlamıştir.

Yukarda bahsi geçenlerden başka; Yesarî Esad Efendi, Hamit Aytaç ve Yahya Fahrettin'den de günümüze nadide eserler kalmıştır.

Bu güzel hüsn-ü hat eserleri ya vakıf binalarını süslemekte veya vakıf kütüphanelerinde bulunmaktadır. Hüsn-ü hattın vakıflarla yakın ilişkisi budur.

Şimdi geldik Medresetül Hattâtîn'e. Yazının özelliğini yitirmeye başlamasıyla Evkaf Nezareti bünyesinde 20 Mayıs 1915 yılında açılmıştır. Çeşitli uğraşılardan sonra Güzel Sanatlar Akademisi'ne bağlanan Medresetül Hattâtîn, burada modernist bakış açısıyla küçümsenerek yok olmaya mahkûm edilmiştir.

Medresetül Hattâtîn hoca ve talebelerinden bazıları; Hulusi Efendi, Kamil Akdik, Ferit Bey, Ressam Ali Sami Bey, Tuğrakeş Hakkı Bey, Hüseyin Tahirzade, Hacı Nuri Korman, Baha Efendi, Necmettin Okyay, Emirzade Kemalettin Bey, Süheyl Ünver, Macit Bey, Halim Efendi.

Medresetül Hattâtîn binası şu an boş ve atıl durmaktadır, ilk gayesine uygun bir çalışma için tahsisinin uygun olacağını düşünüyorum" diyen Derman, sözlerini bu cümle ile tamamladı.

Sonrasında İstanbul Teknik üniversitesi Mimarlık Fakültesi öğretim üyesi Dr. Aras NEFÇi “Mima- 


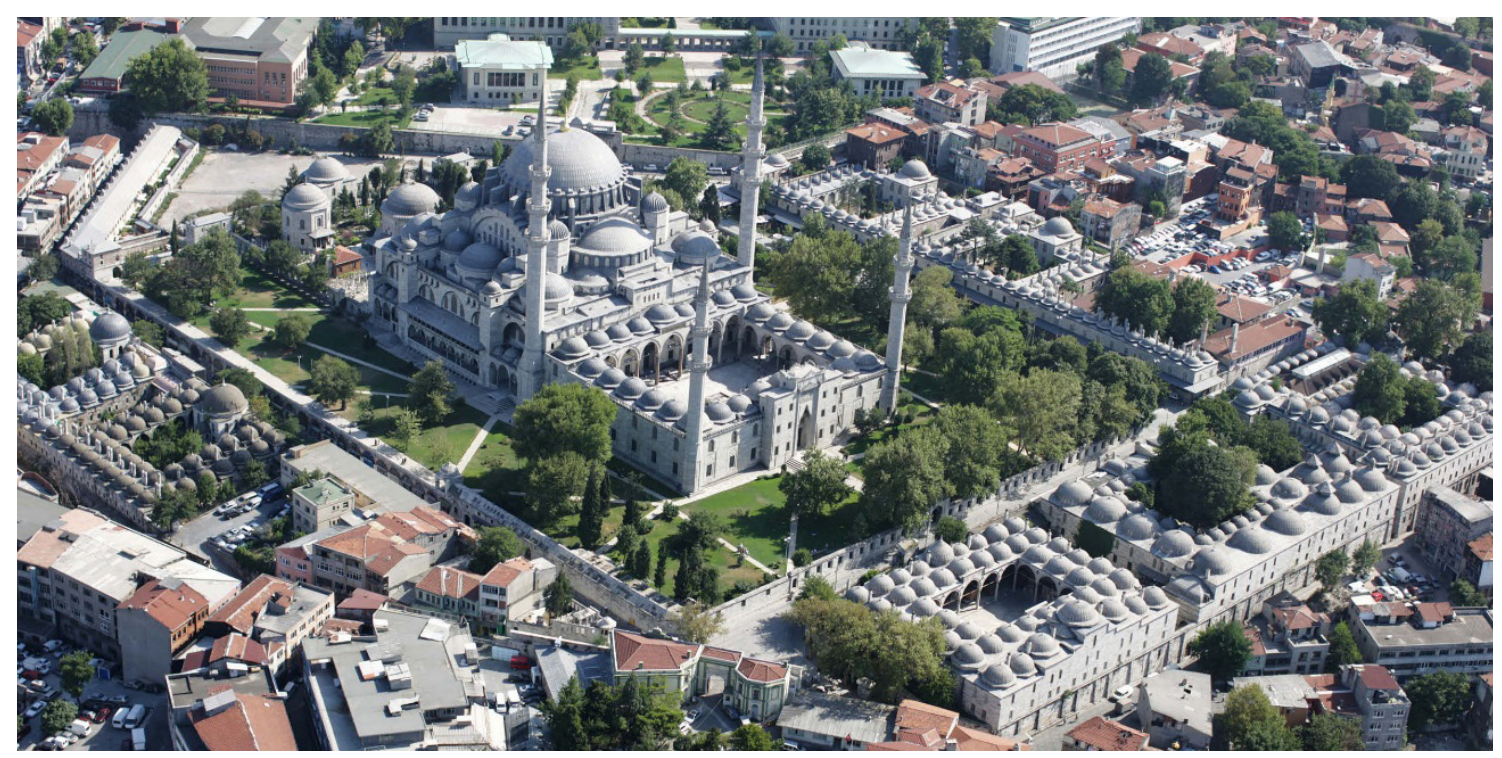

Resim 3. Süleymaniye Külliyesi.

ri'de Vakıf İzleri" konulu bildirisini zengin görsel içerikle birlikte sunmuştur.

Nefçi, bildirisinin hülasasında vakıf mimari eserlerinin şehirlerin sembolü olarak nasıl belleklerimizde yer aldığını ifade etmiş ve konuşmasında, özet olarak, şu detaylara yer vermiştir;

“Deseler ki: Hangi mimari program veya üslup Osmanlı Devleti'ni bir tek komplekste, bir tek külliyede temsil eder; bence Süleymaniye'dir. Süleymaniye külliyesi hem Osmanlı hem İslâm mimarisinde doruk noktadadır. Hem mimari tasarım, hem program, hem de şehircilik tasarımı açısından hakiki anlamda bir mimarlık, şehircilik eseridir. Tabi bu külliyede her şey vakıftır. Kız kulesinden sonra İstanbul'u en çok anlatan fotoğraflardan biridir Süleymaniye fotoğrafi.

Dört yarım kubbeli camilerin ilk denemesi Maraş Ulu Camisidir ancak dört yarım kubbeli camilerin en mütekâmil olanı Fatih Camiidir. Dört yarım kubbeli olan çoktur ama bu güzel oranı hiç birinde yakalayamayız. Selatin camilerinde müstakil olarak yapılan ilk vakıf kütüphane de Fatih Kütüphanesidir.

Üsküdar'daki Atik Valide Sultan Külliyesi de muhteşem bir vakıf eserdir yıllar önce medresenin duvarları yıkılarak hapishane olarak kullanılmış, şimdi ise restore görüyor ve enstitü olarak görev yapacak.
Fatih'te Küçük Efendi Camii Feyziye namıyla, oval şekilde bir camidir ve mihrabında çilehanesi olan üç camiden birisidir.

Nuruosmaniye bana göre Osmanlı'nın ikinci Süleymaniye'sidir. İtirazlar olabilir ancak basit bir ölçüm sonucu olarak bunu ifade edebilirim. Ayasofya oval bir kubbeye sahiptir, uzun tarafi $34 \mathrm{mt}$. kısa tarafi $31 \mathrm{mt}$.dir, Süleymaniye 27,40 mt.dir fakat $25.50 \mathrm{mt}$. çapında en büyük kubbe Nuruosmaniye'dir, Sultanahmet'ten de Yavuz Selim'den de büyüktür. Böyle büyük bir kubbe dört kemer üzerine oturur. Bu külliye de camisi, medresesi, imareti ve kütüphanesi ile bir vakıf eserdir.

Ragıp Paşa Kütüphanesi, dünyanın en güzel müstakil vakıf kütüphanelerinden biridir. Bozdoğan Kemeri, su ve yaya yolunu barındıran muhteşem vakıf eserlerindendir. Yine Sinan'ın mühendislik açısından en muhteşem eserleri arasında Büyükçekmece Köprüleri de bulunmaktadır.

Cami, medrese, mektep, kütüphane, şifahane, imaret, çeşme, köprü, su kemerleri, kuş evleri ve diğer vakıf eserler; şehir halkına hizmet sunduğu kadar estetik ve fonksiyonelliğe de büyük önem vermiştir" diyen Nefçi konuşmasını kuş evlerinin estetik ve fonksiyonellik örnekleriyle tamamlamıştir.

Son olarak Ankara üniversitesi Dil-Tarih ve Coğrafya Fakültesi Sanat Tarihi Bölümü öğretim Üye- 
si Yrd. Doç. Dr. Rüstem BOZER “Vakıf Eserlerde Ahşap Sanat" konulu tebliğini sunmuştur.

Ahşap eserlerin hem Selçuklu 'da hem de Osmanlı'da istisna sayılabilecek bir ya da en fazla iki örnek dışında hemen hemen tümünün vakıf eseri olduğunu belirterek başladığı tebliğinde, özetle, şu detaylara yer vermiştir;

"Bir cümle okumak istiyorum, dikkatinizi de çekmek istiyorum; 'Ahşap Oymacılığı Selçuklu Çağı sanatına Büyük Selçuklu Egemenlik alanlarından, Orta Asya, Iran, Azerbaycan, Gürcistan Irak ve Suriye'den ve güneyde Eyyubi ve Memluk egemenliğindeki bölgelerden ithal edilmiştir.' Bu cümle bana ait değil, bu alanda çalışma yapan büyük bir hocamızın. Ancak ben bu görüşe katılmıyorum. İslam Coğrafyasında ortaya konulan eserlerin tamamının ithal bir kültürün ürünü olduğu tespiti bulunmaktadır ancak ben bu görüşe katılmıyorum, tüm bu sanat eserlerinin medeniyetimizin ürünü olduğu fikrini benimsiyorum.

Selçuklu dediğimiz zaman bütün unsurlarından soyutlanmış bir toplumdan bahsetmiyoruz. Sadece aynı coğrafya yaşayan insanların, hayatlarının bir döneminde kurduğu bir devletten bahsediyoruz. Dolayısıyla oradaki devlet sanat ve işçilik unsurlarından soyutlanmıyor, toplumda var olagelmiş unsurlar zaten devam ediyor. Türkler Anadolu'ya gelirlerken zaten yanlarında getirmişlerdir, ithal ederek değil. 9. yüzyıl Abbasi döneminden bir taç ahşap parça; bu bir oymadır ama uluslararası literatüre girdiği haliyle eğri kesim ya da mai kesim denilen bir üsluptur, dünya literatüründe tarandığı zaman Asya'da Türklerin kullandığı, başka bir coğrafyada kullanılmayan bir teknik olduğunu görürsünüz.

9. yüzyıl Samarra İslam Sanatının kilit noktalarından birsidir. Abbasi Halifesi Türkler için bir şehir kurduğunda yalnızca askerler gelmiyor o şehre, askerler yanında ilim adamları, sanatkârlar ve kültür adamları da geliyor. O şehir işte bunun İslam coğrafyasına yayılmasına vesile olan şehirdir. Emevi sanatiyla Abbasi sanat arasında neredeyse bağlant yoktur. Her şey bu şehre yerleşen Türklerin etkisiyle başlamıştır.

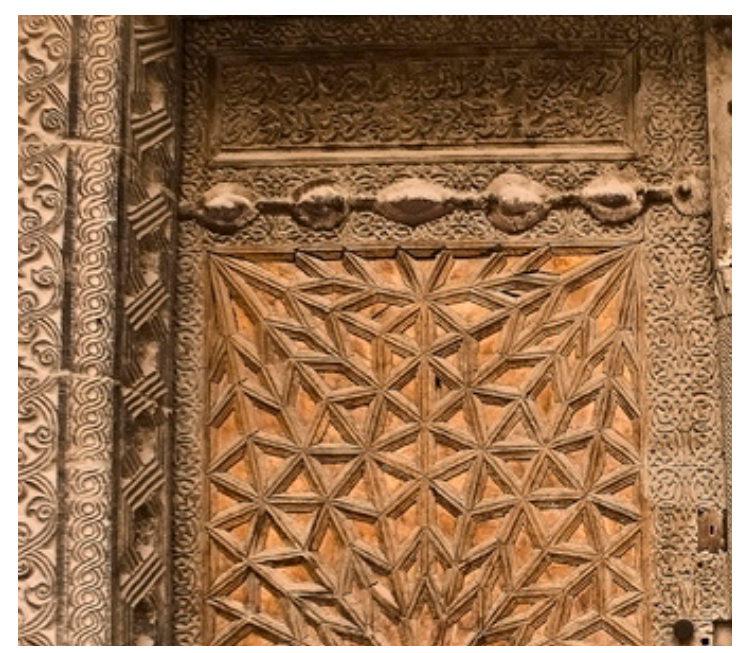

Resim 4. Niğde Sungur Bey Camiinin künde kari kapısı.

Ahşap eserlerin müzelere alınması; aslında eserin yapıldığı ve uzun zaman bulunduğu ortamdan alınması anlamına da geldiği için eserin yıpranmasını hızlandırmaktadır. Bunula beraber binaların zayıf halkasından biri ahşaptır. O ahşapların en zayıf halkası ise kapı kanatlarıdır; binanın kitabesi de kapı kanatlarıdır. Ortaçağda binanın kapısında kitabe varsa, binanın başka yerinde kitabe bulunmamaktadır.

Niğde Sungur Bey Cami devrinin en güzel künde kari örneğidir. Bu kapı kendi kitabesini taşımaktadır. Bu durumda bu kapının binasından sonra yapıldığını anlıyoruz.

Ankara, ortaçağda, Selçuklunun erken dönemlerinden Osmanlı'ya kadar olan döneminde devrinin en iyi ahşap ustalarına sahiptir.

İmitasyon eserlerin uzmanlara danışılmadığından yapılması nedeniyle aslına benzemeyen eserler orijinal kapı yerine takılmakta ve bu imitasyonların aslına benzememesi nedeniyle ilgililerin yanlış bilgilenmesine, basılı yayınlara yanlış bilgi girilmesine neden olmaktadır.

Sultanahmet Camii avlu kapılarının restore edilmesine artık sıra gelmeli sayın Genel Müdürüm" sözleriyle sunumunu tamamlayan Bozer, sözü oturum başkanına bırakmıştır.

Soru ve cevaplar kısmını takiben, Vakıflar Genel Müdürü Sayın Dr. Adnan ERTEM, panelistlere plaket ve hediyeleri takdim ettikten sonra panel sona ermiştir. 